\title{
Joining of Metal-Plastics-Hybrid Structures Using Laser Radiation by Considering the Surface Structure of the Metal
}

\author{
Christian Hopmann, ${ }^{1}$ Suveni Kreimeier, ${ }^{1}$ Jan Keseberg, ${ }^{2}$ and Carsten Wenzlau ${ }^{2}$ \\ ${ }^{1}$ Institute of Plastics Processing (IKV) at RWTH Aachen University, Seffenter Weg 201, 52070 Aachen, Germany \\ ${ }^{2}$ Leister Technologies AG, Galileo-Strasse 10, 6056 Kaegiswil, Switzerland \\ Correspondence should be addressed to Suveni Kreimeier; suveni.kreimeier@ikv.rwth-aachen.de
}

Received 19 July 2016; Accepted 18 September 2016

Academic Editor: Zhong-Ming Li

Copyright (c) 2016 Christian Hopmann et al. This is an open access article distributed under the Creative Commons Attribution License, which permits unrestricted use, distribution, and reproduction in any medium, provided the original work is properly cited.

\begin{abstract}
Lightweight construction is a central technology in today's industrial production. One way to achieve the climate goals is the production of hybrid compounds of metal and plastic. The manufacturing process for these hybrid parts can be divided into inmold assembly and postmold assembly. The postmold assembly includes thermal joining by laser, which is applied in the context of this paper. For the investigations, four plastics (MABS, PA6.6-GF35, PP, and PC), which differ in their properties, and three metals (unalloyed steel, stainless steel, and aluminum) are combined and analyzed. These materials have been used, since they have a huge significance in the automotive industry. Preliminary studies showed that an adhesive bond between the two materials is achieved using metal with a structured surface. According to these studies, three structuring processes for metals (selective laser melting (SLM), NRX, and a welded metallic tissue) are tested. The quality of the material/structure combinations is tested in tensile-sheartests, microscopy images, and alternating climate tests. Compounds with SLM-Structure achieve highest strength, while compounds with aluminum are much more complex to manufacture.
\end{abstract}

\section{Introduction}

Lightweight construction is one of the key technologies of the 21st century. In addition to the substitution of metals by lighter materials, lightweight construction includes also a selective combination of different materials in order to combine their advantages. One of these combinations is the so-called hybrid compound of metal and plastics. Examples can be found in the automotive sector in the front end of the Ford Focus or the pedal block of the Mercedes-Benz C-Class. The use of hybrid compounds in these areas leads to a cost and weight reduction as well as an increase of the functional integration.

The production of hybrid parts is carried out by either in-mold assembly or postmold assembly. Postmold assembly involves, beside mechanical joining and bonding, also thermal joining. Thermal joining includes joining of metalplastics-hybrid compounds by heat contact, ultrasonic induction, and laser radiation and was part of several studies
[1-18]. The studies identified some limitations and problems of the processes. For example, ultrasonic welding has low flexibility of the sample geometry as well as a small joining area [2]. In contrast, the challenges of induction welding are primarily in the process layout and control concerning the easily influenced magnetic field and extremely high heating rates [2].

Metal-plastics-hybrid joining by laser radiation is not industrialized yet, because basic conditions like long-term strength or the process control have not been experienced deeply enough.

The thermal joining by using laser radiation has been studied in different combinations. During the joining of lasertransparent or partially laser-transparent plastics with metals, the metal component is used as a laser beam absorber. In this way, the plastic is locally heated above the melting point and holding forces are formed between the joining partners. The high flexibility in terms of the joining geometry as well as the extremely short cycle time qualifies this process for 
an application in the medium- and large-scale production. The thermal joining with laser radiation has been investigated in different combinations of materials, such as Polyethylene terephthalate (PET) with steel $[4,19,20]$ or Polyamide 6 (PA6) or Polyamide 66 (PA66) with unalloyed steels [21, 22]. Under the influence of external forces, the contact between the joining partners affects the wetting of the metal surface. However, if transparency is not given, the metal is heated by direct irradiation [12, 22-29].

Bauernhuber and Markovits have been concerned with the joining of PMMA and steel by using pulsed Nd:YAGlaser. On the one hand, the influence of process parameters (heating time, laser setting, surface roughness, and joining pressure) on the weld strength has been investigated. On the other hand, the temperature distribution was determined during different heating conditions. Thus, higher surface roughness, due to mechanical anchors, results in a higher weld strength. During the joining process, there was blistering in the material which weakens the weld but can be controlled via the joining pressure $[21,22]$.

Schricker et al. used present results of PA66 and EN AW 6082 to transfer these to macroscopic structures in order to find the optimal alignment angles for different structures (drilled holes and grooves). The investigation shows that the determined shear force is independent from structure (geometry and alignment angle). However, the alignment angle depends on the relative structure; for example, the alignment angle for grooves is $-45^{\circ}$ [30].

Previous investigations $[4,12,19-31]$ show that the type of surface structure of the metallic joining partner has an important influence on the bond strength. The highest bond strength was achieved using structures with undercuts. So far, such structure could only be applied by laser technology [32].

In order to investigate the applicability and requirements of laser joining of hybrid compounds, bonded samples are examined in strength tests as well as alternating climate tests. Furthermore, the bond strength was investigated regarding metallic material and their surface structure. For this purpose, four plastics and three metals with three different surface structures were investigated. The plastics used are methyl-methacrylate-acrylonitrile-butadienestyrene (MABS), Polyamide 6.6 with 35 wt.-\% glass fibers (PA6.6-GF35), polypropylene (PP), and polycarbonate (PC). They differ from each other in optical, rheological, thermal, and mechanical properties. In addition, three different metallic materials (unalloyed steel, stainless steel, and aluminum) were utilized. The surface structure was applied by using three common technologies: SLM-Process, NRX-Technology, and welding of a metallic tissue.

\section{Test Procedure}

2.1. Sample Geometry. The plastics sample with a basic size of $45 \times 80 \mathrm{~mm}^{2}$ has stepped jumps from $1 \mathrm{~mm}$ in thickness direction. The thickness of the steps extends from $1 \mathrm{~mm}$ to $4 \mathrm{~mm}$. The metallic joining partner is a cuboid with the dimensions $80 \times 25 \times 3 \mathrm{~mm}^{3}$. The structured area of the sample starts at one sample edge and extends over the whole width with a length of $12.5 \mathrm{~mm}$, making a joining area of $25 \times$

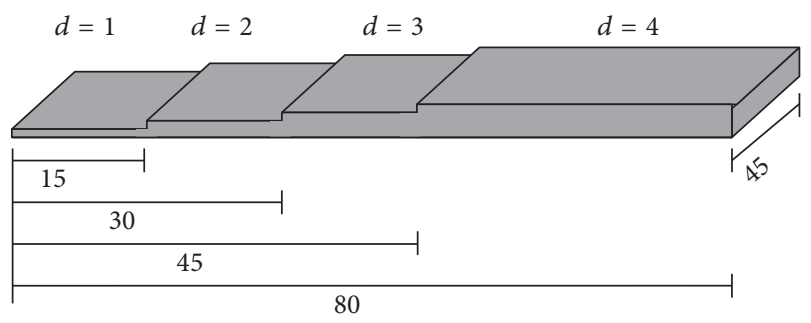

(a)

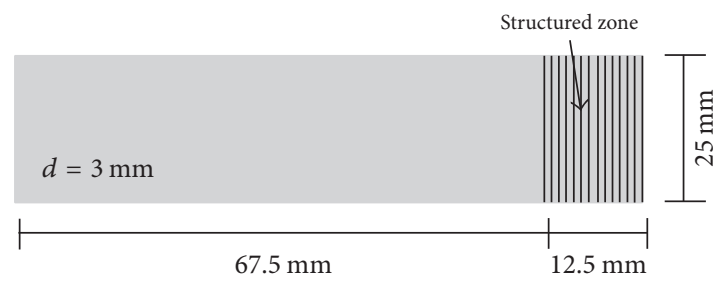

(b)

FIGURE 1: Geometry of the plastic (a) and metal sample (b).

$12.5 \mathrm{~mm}^{2}$ available. Figure 1 shows the geometry of both samples.

2.2. Joining with Laser. During laser joining of hybrid compounds, the metal absorbs the irradiated laser energy and converts it into heat. The laser radiation can be applied in two ways. In the first method, the polymer sample is positioned above the metal sample. Laser radiation transmits through the polymer before it is absorbed in the metal (Figure 2).

The heating is carried out by thermal conduction and radiation in the joining zone.

In the second variant, the metal is placed above the polymer sample and is directly irradiated by the laser. The generated heat is transported by thermal conduction through the complete thickness of the metal sample into the joining zone. This type of heating requires more time and energy than the first method and is therefore not preferred. However, the first variant is only possible for plastics with high transmission properties. Otherwise the laser radiation is already converted into heat in the polymer and cannot expand into the joining zone. The direct radiation of the metal is only used for material combinations which are not joinable with the transmission technique.

In this study, the system was configured to heat the joining zone homogeneously in short time. For the experiments, Leister Technologies AG, Kägiswil, Switzerland, provided a diode laser source (LineBeam) that distributes a homogeneous line direct out of the diode stack with an optical power of maximum $600 \mathrm{~W}$. In order to prevent back reflection of radiation into the laser module, the LineBeam is assembled under an angle of $4^{\circ}$.

The line laser is moved across the joining area at a constant joining pressure of $0.4 \mathrm{MPa}$. For homogeneous melting of the plastics, the laser is moved across twice. The first crossing preheats the metal, while the second crossing heats to the final joining temperature. In order to prevent the 


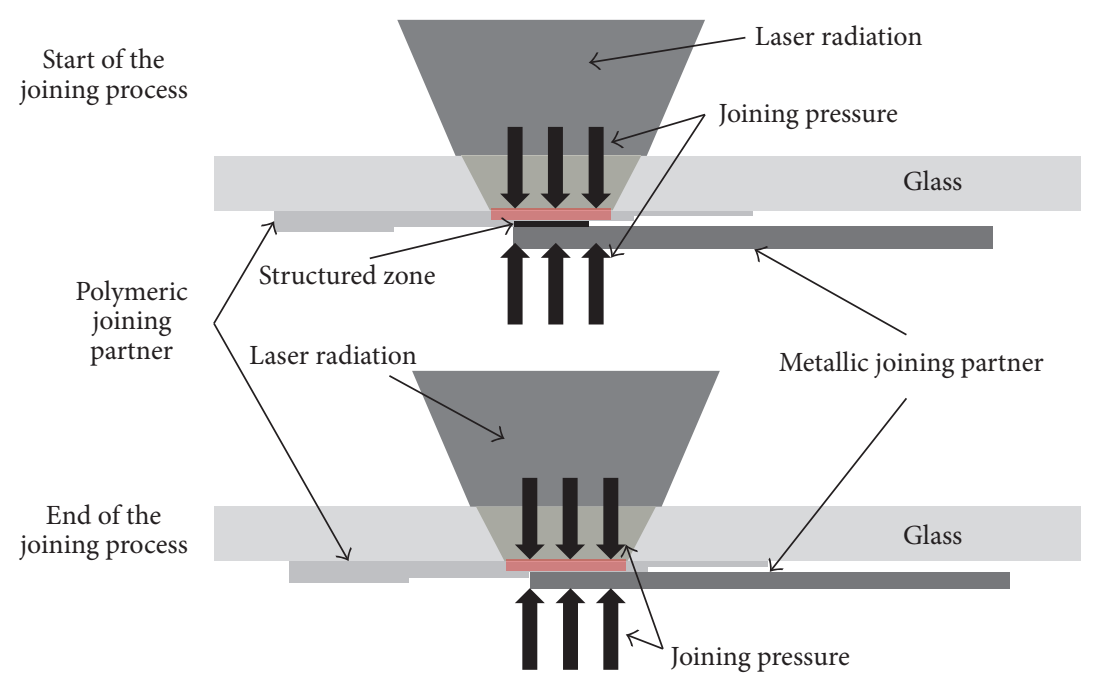

FIGURE 2: Schematic illustration of the transmission technique with laser (first method).

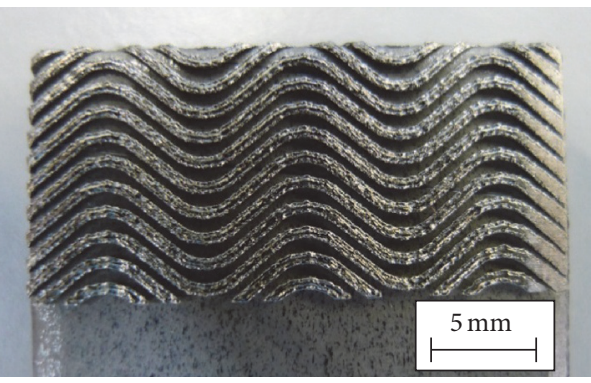

Figure 3: SLM-Structure.

plastics from damage due to higher temperatures, the temperature may be monitored using a pyrometer. Heating of the metal until the melting temperature of the plastics is reached ensures that the melted plastics can flow into the cavities of the structure. In this way, "mechanical interlocking" occurs during cooling. The cooling takes place at a constant joining pressure as long as all melt is solidified inside the joining area.

2.3. SLM-Process. The selective laser melting- (SLM-) Process belongs to the group of additive manufacturing. During the manufacturing process, a powder material is applied on a base sheet, which is positioned on a lowerable working table. By laser radiation, according to CAD parameters, the powder is melted locally. After fully generating structure on one layer, the working table is moved down by a layer thickness. These steps are repeated until the desired structure (Figure 3 ) is obtained $[32,33]$.

2.4. NRX-Technology. The NRX-Technology is a mechanical method which is protected by Nucap Industries Inc., Toronto, Canada. The surface structure is created with a chisel tipped roller. When the chisel tipped roller is in contact with the metal plate, small hooks are dislodged from the plate. However, the caused hooks are still connected to the plate.

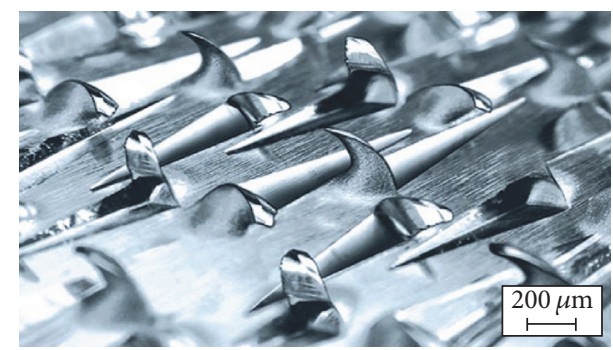

FIGURE 4: The NRX-structured sheet (NRX Factor Limited, Toronto, Canada).

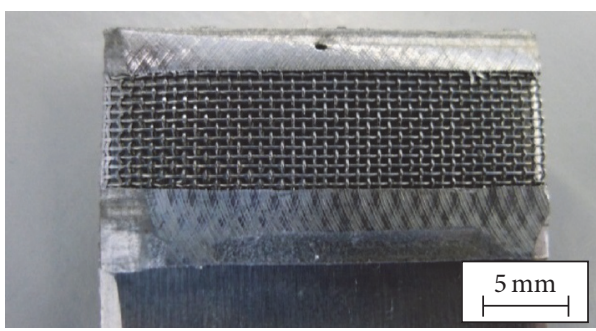

Figure 5: Metallic sample with welded metallic tissue.

The size of the resulting hooks (Figure 4) depends on the size of the chisels.

2.5. Welding a Metallic Tissue on Metal. The welding of a metallic tissue also belongs to the group of surface structures, but the surface of the metal is untreated. The base material and the material of the metallic tissue are the same. The undercuts of the metallic joining partner are produced via the welding of a metallic tissue (Figure 5). The used tissue has a wire size of $0.2-0.3 \mathrm{~mm}$ and a mesh size of $0.4-0.5 \mathrm{~mm}$. The welding is executed over the entire width of the sample, in a way that the tissue does not relieve from the base material. The additional stripes welded on the side are necessary for a stronger bond 


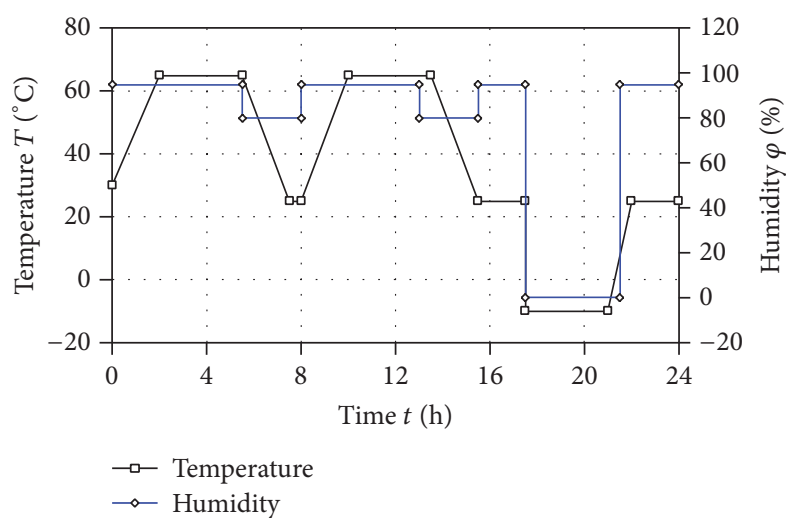

FIgURE 6: Temporal course of the test temperature and humidity during a cycle of the alternating climate test.

between the tissue and base material but may cause notch effects.

2.6. Tensile-Shear-Tests. The joining tests are evaluated using two techniques, a tensile-shear-test according to DIN ISO 527 [34] and microscopy images. The microscopy images should illustrate both the connection between plastics and metal and the filling of the structures in the joining area. The metalplastics-hybrid joining is based solely on adhesion and form closure. Tensile tests showed that the joining strength of the tested combinations reaches a plateau over a wide range of energy input. Too much energy leads to visual destruction of the plastic material, before the strength may decrease. The reason is that the polymeric joining partner will not be damaged or degraded at the optimized joining temperature [35]. Overall, achieving a breaking force that exceeds the basic material strength of the respective polymers is desirable and implies a cohesive failure of the compound, since an adhesive failure means a failure in the boundary layer itself.

2.7. Alternating Climate Test. With the alternating climate test, the climate stability of the compounds is determined. For this purpose, compounds with a good bonding strength are examined in an alternating climate cycle according to DIN IEC 60068-2-38 [36]. The chronological sequence of the cycle, which is repeated six times, is shown in Figure 6. After the alternating climate test, the weathered compounds are subjected in a tensile-shear-test in accordance with DIN ISO 527, too [34]. The influence of the alternating climate tests on the bonding strength is obtained through a comparison with results of the unweathered compounds.

\section{Discussion of the Results}

3.1. Optical Properties. The transmission technique requires high transmittance $\tau$ of the plastic as well as a high absorption factor $\alpha$ of the metal. In contrast, the direct irradiation of the metal is independent from the plastics optical properties. In this case, only a high absorption factor is required. The influence of the reflection factor $\rho$ can be neglected.
TABLE 1: Optical properties of the plastics samples at the wavelength of $940 \mathrm{~nm}$ and a sample thickness of $2 \mathrm{~mm}$.

\begin{tabular}{lcccc}
\hline Parameter/plastic & MABS & PA6.6-GF35 & PP & PC \\
\hline$\tau[\%]$ & 92 & 41 & 63 & 89 \\
$\rho[\%]$ & 8 & 36 & 30 & 11 \\
$\alpha[\%]$ & 0 & 23 & 7 & 0 \\
\hline
\end{tabular}

TABLE 2: Optical properties of the metal/structure combinations at the wavelength of $940 \mathrm{~nm}$.

\begin{tabular}{lcc}
\hline Material/structure & $\alpha[\%]$ & $\rho[\%]$ \\
\hline aluminum/NRX-Structure & 30 & 70 \\
stainless steel/NRX-Structure & 48 & 52 \\
unalloyed steel/NRX-Structure & 67 & 33 \\
stainless steel/SLM-Structure & 61 & 39 \\
unalloyed steel/SLM-Structure & 58 & 42 \\
aluminum/welded metallic tissue & 49 & 51 \\
stainless steel/welded metallic tissue & 76 & 24 \\
unalloyed steel/welded metallic tissue & 84 & 16 \\
\hline
\end{tabular}

The optical properties of the samples are determined using a UV-VIS Spectrometer type Lambda 1050 by Perkin Elmer Corporation, Waltham, USA. The results of the optical properties show that the amorphous thermoplastics PC and MABS have transmittance of around $90 \%$ at the relevant wavelength of $940 \mathrm{~nm}$. Therefore, the amorphous thermoplastics require a lower laser power in order to achieve a connection between the two joining partners than the two semicrystalline polymers PA6.6-GF35 and PP (Table 1). The semicrystalline thermoplastics have significantly lower transmittance due to the refraction of light at the crystalline structures as well as the glass fibers in PA6.6-GF35.

The highest absorption factor of the metals, independently of the structure, has unalloyed steel, while aluminum provides the lowest. A comparison of the absorption factors in dependency of the various structures shows that the welded metallic tissue reaches the highest value (Table 2).

3.2. Results for Compounds with MABS. According to preliminary test, compounds with MABS can be produced with the transmission technique. However, the maximum joining power depends on the metallic joining partner.

Furthermore, a parameter combination to join aluminum with welded tissue and MABS could not be discovered. The plastic sample simply pyrolyzes before joining.

3.2.1. NRX-Structure. Metal samples with NRX-Structure create a cohesive failure when a complete connection between the samples is given. Up to a joining energy of $3.0 \mathrm{~kJ}$ the samples fail adhesively, afterwards cohesively (Figure 7). This shows that the compound of plastic and metal can absorb higher forces than the plastic sample itself. The required energy for a complete connection of the plastics to the metal differs considerably between the metals. For example, aluminum needs a joining energy three times higher than both stainless steel and unalloyed steel (10 kJ). 

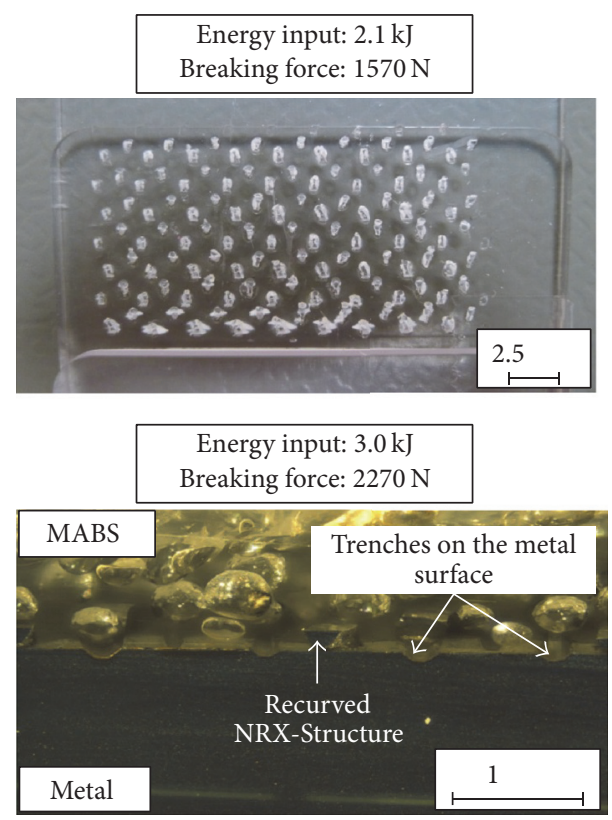

FIGURE 7: Connection of MABS samples and unalloyed steel with NRX-Structure.

3.2.2. SLM-Structure. The results of compounds with MABS and SLM-Structure provide the same effect as MABS and NRX-Structure. The change from adhesive to cohesive fracture is slightly above the NRX-Structures. Similar to the NRX-Structure is the transition $(2.3 \mathrm{kN})$ between adhesive and cohesive failure for stainless steel and unalloyed steel by applying the same energy input $(2 \mathrm{~kJ})$.

3.2.3. Welded Metallic Tissue. The strength behavior of MABS and metal samples, which are occupied with a welded metallic tissue, differs from the other two structures. The breaking force increases with increasing joining energy until the transition between cohesive and adhesive failure is reached. As soon as the decomposition temperature is achieved, the breaking force decreases instead of reaching a limiting value (Figure 8).

Since the surface of the metallic tissue is reticular, the plastic material has uneven contact. In consequence, plastic sample heats at different rates. At places with contact, the plastic heats conductively. The other areas heat by convection, which requires both more time and higher temperature (see Figure 5). But higher temperature leads to decomposition of the plastics material in the conductively heated areas.

A precise classification between the two fractures cannot be determined with these samples. One reason is the sharpedged additional material that causes notch effects. Another reason is the impact of the initiating decomposition of the plastic to the material strength.

3.2.4. Alternating Climate Test. After execution of the alternating climate tests, a dependency of the metallic joining partner and structure on the strength behavior has been discovered. The alternating climate test has no influence on the strength of the compounds with SLM-Structure. The

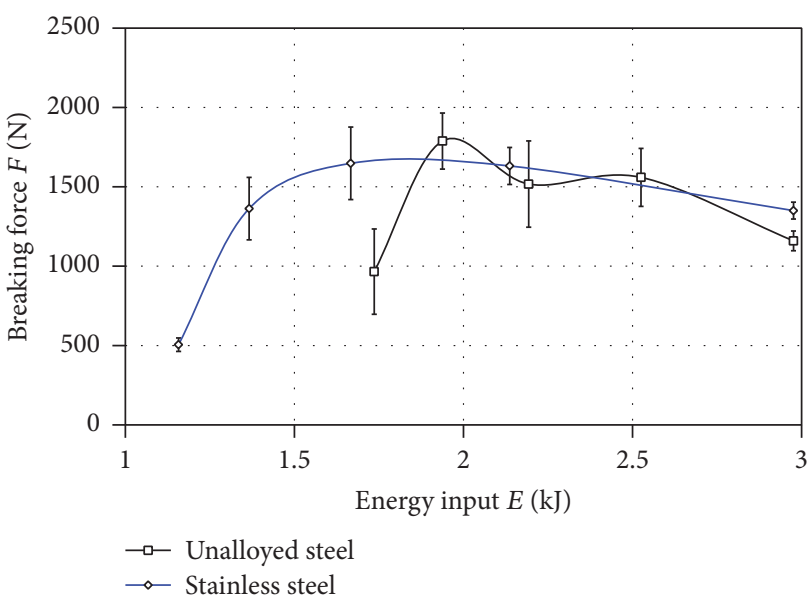

FIgURE 8: Course of the breaking force of MABS with tissue structured metal on the energy input.

measured strengths before and after the alternating climate tests are the same.

Samples with welded tissue react similarly if the compound breaks cohesively in unweathered condition. If it breaks adhesively, the strength decreases. The fact that compounds are destroyed cohesively independently of weathering proves that the alternating climate test has no influence on the basic material strength of MABS.

Regardless of the metallic material, a loss of strength is discovered by compounds with NRX-Structure after the alternating climate test. A reason may be the different thermal expansion of plastics and metal, which loosen the connection and lead to a less strong joint. This only appears with the NRX-Structure, since this structure can only absorb forces in one direction. With the other structures, which can absorb forces in all three directions, the influence of the thermal expansion can be neglected, as long as the structures are filled completely.

3.3. Results for Compounds with PA6.6-GF35. Similar to MABS, PA6.6-GF35 can be welded using the transmission technique. Due to the significantly higher melting temperature $\left(T_{M}=260^{\circ} \mathrm{C}\right)$ of PA6.6-GF35 in contrast to MABS $\left(T_{M}=110^{\circ} \mathrm{C}\right)$, a connection of PA6.6-GF35 and aluminum with NRX-Structure cannot be realized. But since internal absorption is higher, the PA6.6-GF35 heats up while the laser radiates through the material and can be joined to the aluminum with welded tissue sample.

3.3.1. NRX-Structure. The combination of PA6.6-GF35 with NRX-structured metal samples shows a nearly linearly increasing breakout force that grows with higher joining energy. Because of the higher material strength [6], even with complete connection of the polymer to the metal sample, no cohesive fracture can be achieved. Therefore, a maximum achievable breakout force can be determined (Figure 9).

3.3.2. SLM-Structure. The joining of metals with SLMStructures and PA6.6-GF35 is not constant, since the inhomogeneous distribution of the glass fibers complicates the 


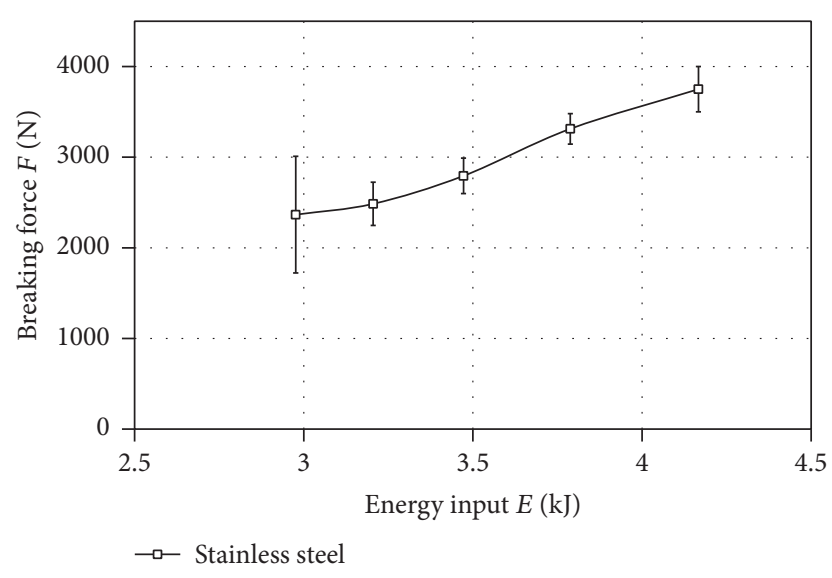

FIGURE 9: Breaking force profile over the energy input of PA6.6GF35 with NRX-structured stainless steel.

production of a reproducible connection between the joining partners. An inhomogeneous distribution of glass fibers could apply locally higher forces to the SLM-Structure, which results in a failure of the structure. Figure 10 shows the microscopic images of PA6.6-GF35 with SLM-structured stainless steel. As illustrated, an increase of the joining energy by $1 \mathrm{~kJ}$ is sufficient to complete the connection between metal and polymer, in which case it comes to a cohesive failure. Although the left picture already shows a "mechanical interlocking," a residual amount of bubbles is visible. An increase of joining energy ensures a decrease of viscosity of the polymer melt. However, the melt can flow to the bottom of the metal structure and the bearable breaking force of the connection is able to achieve higher value than the material itself.

3.3.3. Welded Metallic Tissue. Similar to the other two structures, an increase of joining energy results in an increase of the bearable force until the cohesive fracture behavior or the strength limit of the tissue is reached.

The limit between a tear-up of the metal tissue and a cohesive failure of the sample depends on the loadable joining area. Above a specific loadable joining area, the required breaking force is so high that the basis material strength of the aluminum tissue is exceeded and the samples fail significantly earlier in the tissue.

3.3.4. Alternating Climate Test. The alternating climate tests result in a decrease of strength in the hybrid compounds with PA6.6-GF35 as polymeric joining partner (Figure 11).

In general, the decrease of the strength can be explained by water absorption of the polymer during the alternating climate test. Water absorption of PA6.6-GF35 may achieve $3.5 \%$ by weight, which reduces the material strength.

An influence of the alternating climate tests on the strength of stainless steel with SLM-Structure can only be observed by high energy input. In comparison, the aluminum with welded tissue samples does not decrease in mechanical strength, independently of climate tests. This is due to the fact that the compounds already break through rupture of the tissue at low forces, even in the unweathered condition.

3.4. Results for Compounds with Polypropylene (PP). In comparison to amorphous thermoplastics, the transmittance of semicrystalline thermoplastics such as PP or PA6.6-GF35 is significantly lower (Table 1). However, the transmittance is high enough for laser transmission joining. One advantage of PP is that it can be joined with all combinations of metal, independently of the structure. This behavior is based on the low melting temperature $\left(T_{M}=163^{\circ} \mathrm{C}\right)$ as well as the low melt viscosity of PP [7].

3.4.1. NRX-Structure. Independent of the used metal with NRX-Structure, a combination with PP can reach the transition to a cohesive failure of the compound. This is caused by the small melting section as well as the good flowability of the polypropylene melt [8]. At a force of $1.3 \mathrm{kN}$, which corresponds to a material tensile strength of $21.5 \mathrm{MPa}$, the transition from the adhesive to the cohesive failure occurs.

According to already mentioned reasons, this transition is way lower when using unalloyed steel compared to aluminum. Using aluminum, temperatures are reached, where the viscosity of the polymer melt is low enough to achieve a complete connection through "mechanical interlocking" of the polymer to the metal.

3.4.2. SLM-Structure. In the case of SLM-Structures, the development of the tear force is dependent on the metal. Furthermore, there is no exact transition from adhesive to cohesive failure, since the samples cannot be joined below an energy input of $1.4 \mathrm{~kJ}$. Above this level, all samples break cohesively.

3.4.3. Welded Metallic Tissue. In contrast to other polymers, PP can be connected with every welded tissue structure. Thereby, a cohesive sample failure can be reached for every material. The needed force for breaking the samples cohesively is approximately $0.9 \mathrm{kN}$.

During the joining process, the polymer material flows into the subjected area of the tissue due to the low melt viscosity. Therefore, the sample cross section is reduced in the area of the tissue. At this point (thinnest sample cross section), the sample fails cohesively (Figure 12). With this structuring, the limit of the mechanical strength from adhesive to cohesive break is approximately $24 \mathrm{MPa}$.

3.4.4. Alternating Climate Test. The alternating climate tests have only an influence on the combination of PP with unalloyed steel, which has the NRX-Structure or the welded tissue.

Compared to the unweathered compounds, tensile strength is lower. This can be argued by the corrosion of the metallic welding partner in the weld seam. Corrosion implements tensions, which reduce the bonding strength. This fact does not occur at the unalloyed steel samples with SLM-Structure, since the material of the applied structure does not match the basis material. Furthermore, the polymer mainly connects with the applied material, so that the 

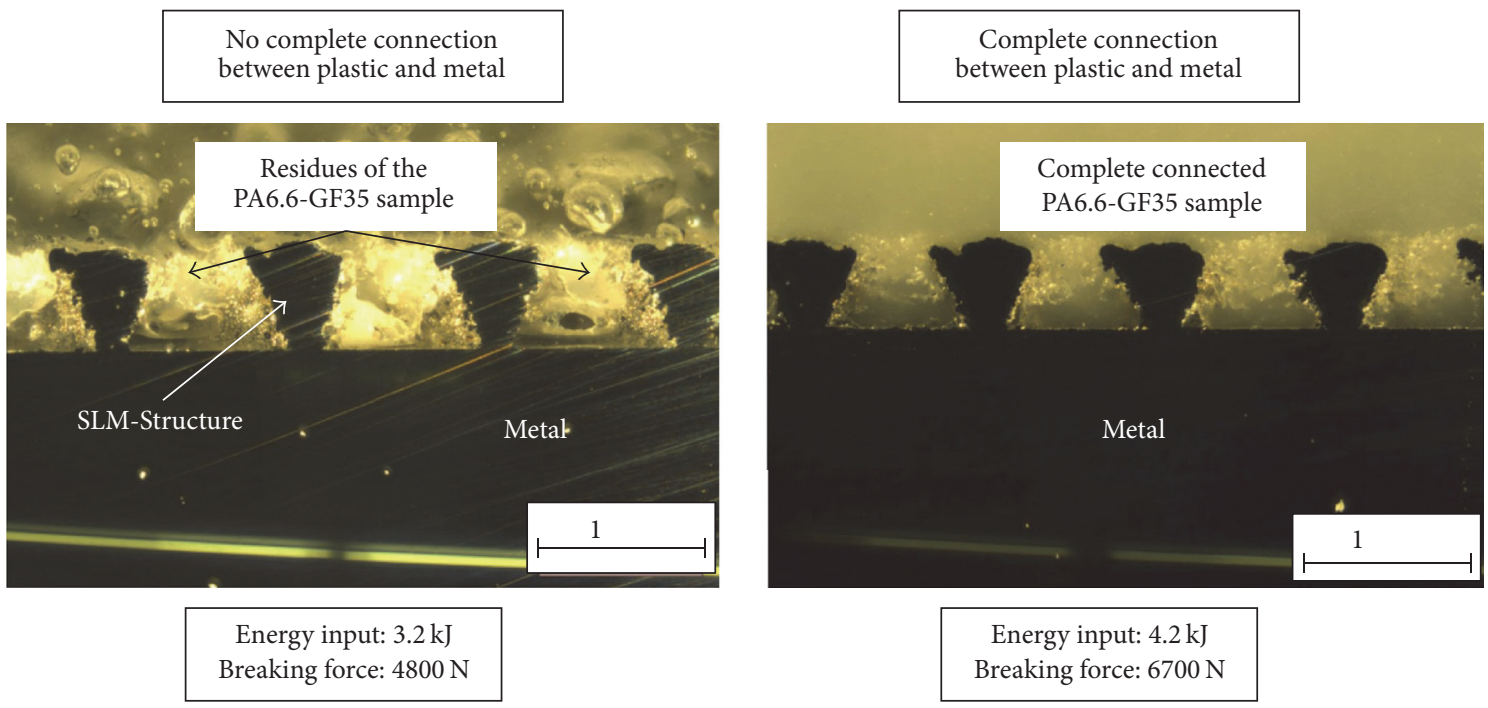

Figure 10: Micrographs of two samples from PA6.6-GF35 with SLM-structured stainless steel.

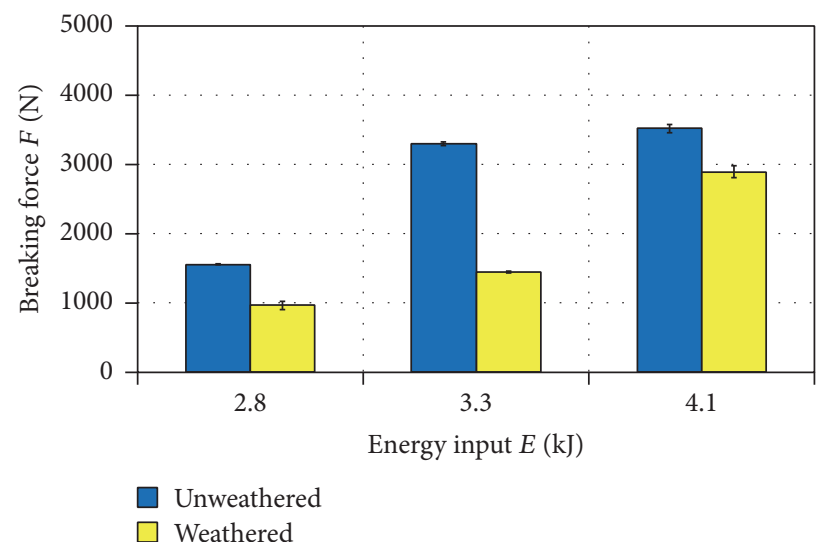

FIGURE 11: Influence of the alternating climate test on the strength using the example of PA6.6-GF35 with unalloyed steel with metallic tissue.

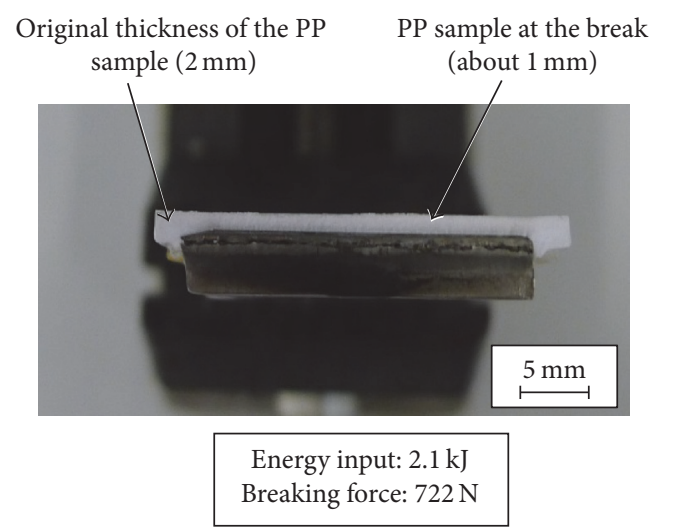

FIgURE 12: Material failure of PP with welded metallic tissue and decreasing sample cross section.

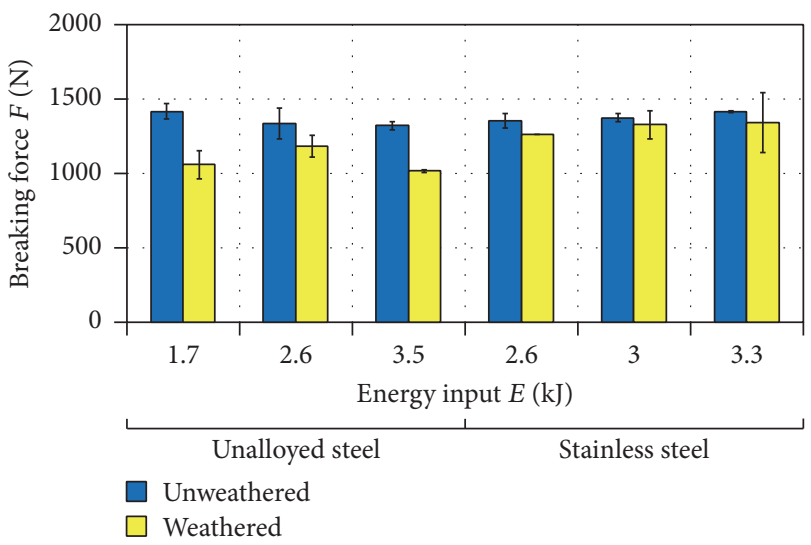

FIGURE 13: Influence of alternating climate test on the connection of PP with stainless steel and unalloyed steel (NRX-Structure).

corrosion of the basis material does not affect the sample strength. Figure 13 shows the influence to the bonding force of unalloyed steel and stainless steel with a NRX-structured surface. The decrease of the strength of the weathered compound with PC and unalloyed steel might be a result of thermal decomposition. When the energy input is too high, thermoplastic materials can disintegrate. This might have happened with the energy input of $3.5 \mathrm{~kJ}$.

3.5. Results for Compounds with Polycarbonate (PC). In contrast to the other polymers, PC is not joined with the transmission technique, because first trials showed a trend for combustion using this method. In general, PC may carbonize applying to much heat locally. In particular in the contact areas, the metal is getting so hot applying laser radiation that PC starts to carbonize. This ends in a dark layer on top of the plastic surface (Figure 14), which increases the absorption coefficient of the PC. Anyway, the PC sample immediately heats up above decomposition temperature and combusts. 


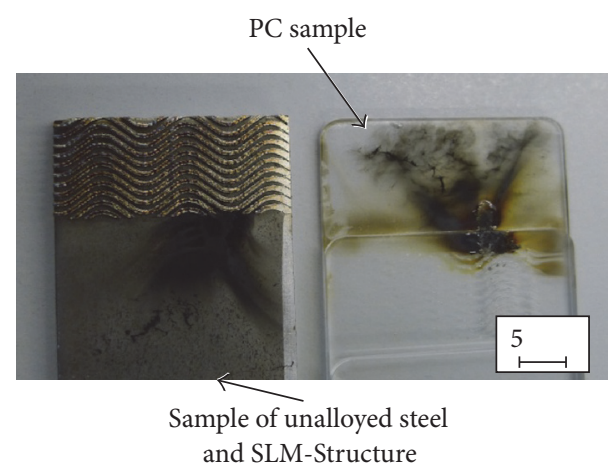

FIGURE 14: Sooted PC samples after the joining test in the transmission technique.

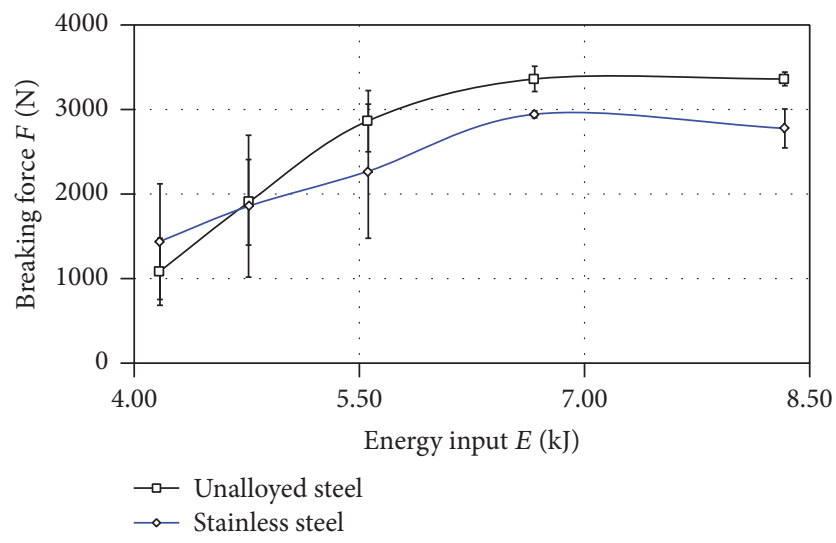

FIGURE 15: Course of the breaking force over the introduced energy for PC with NRX-Structure.

For this reason, the PC is joined to the metallic partner by direct irradiation. For this purpose a temperature above the melting temperature $\left(T_{M}=148^{\circ} \mathrm{C}\right)$ has to be reached inside the joining zone. Since the heat penetrates through the whole metallic sample, the required welding energy is considerably higher than in the transmission joining process.

3.5.1. NRX-Structure. The breaking force of the PC samples with NRX-structured metals rises with increasing energy input up to a maximum amount. The value of stainless steel sample is approximately $3400 \mathrm{~N}$, while unalloyed steel is about $3000 \mathrm{~N}$. Independent from the used metal, this maximum is reached at an energy of $6.7 \mathrm{~kJ}$ (Figure 15). At this breaking force, the stainless steel samples may break both ways cohesively or adhesively.

The difference in the strength of the used metals may be determined by dirt on the surface of the unalloyed steel samples. Due to this layer of dirt, the PC sample can slip off the basis sheet of the metal sample and fail at low forces adhesively.

3.5.2. SLM-Structure. The compounds of PC and metal samples with SLM-Structure have strength maxima which are only $0.3 \mathrm{kN}$ higher than the strength maxima of the

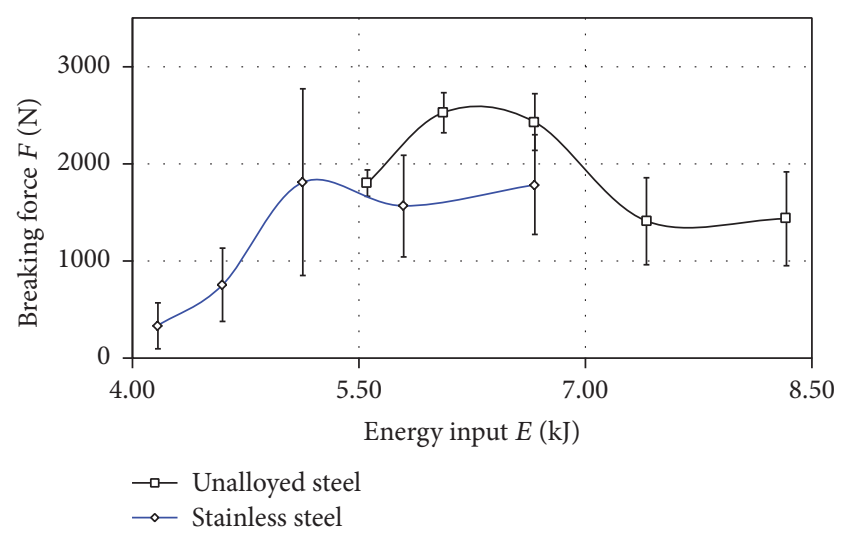

FIGURE 16: Breaking force profile of PC and metal welded metallic tissue.

compounds with NRX-Structure. In contrast to the NRXStructure, the needed energy input for reaching these strength maxima with unalloyed steel samples is $8.5 \mathrm{~kJ}$, while the welding energy for stainless steel is the same as with the NRX-Structure $(6.7 \mathrm{~kJ})$. At these energies, the transition from adhesive to cohesive failure occurs. Due to the undercuts of the SLM-Structure, the layer of dirt does not have an influence on the bonding strength, since the undercuts result in a kind of "mechanical interlocking."

3.5.3. Welded Metallic Tissue. In comparison to the other two structures, a considerable lower energy input is needed to reach the transition from adhesive to cohesive material failure. With unalloyed steel, this transition is reached at a joining energy of $5.1 \mathrm{~kJ}$, while stainless steel requires $6.1 \mathrm{~kJ}$ for the transition.

Furthermore, the breaking force decreases after the transition from adhesive to cohesive failure with rising energy input (Figure 16). After reaching the transition, the material is damaged through the increase of the joining temperature to temperatures above the decomposition temperature.

3.5.4. Alternating Climate Test. Similar to the compounds with PA6.6-GF35, the alternating climate test has an influence on the mechanical strength in the hybrid compounds with PC as polymeric joining partner. The breaking force of the combination of unalloyed steel with SLM-Structure (Figure 17) is reduced. It is remarkable that the decrease of the breaking force increases with rising energy input.

The fundamental decrease of the sample strength as well as its dependence on the joining temperature can be explained by a degradation of the molecular weight of the PC during the joining process [37]. Here, beginning polymer degradation can be assumed.

\section{Conclusion and Outlook}

The studies for the production of metal-plastics-hybrid compounds presented in this paper could be evaluated using several important test criteria. Aside from the achievement 


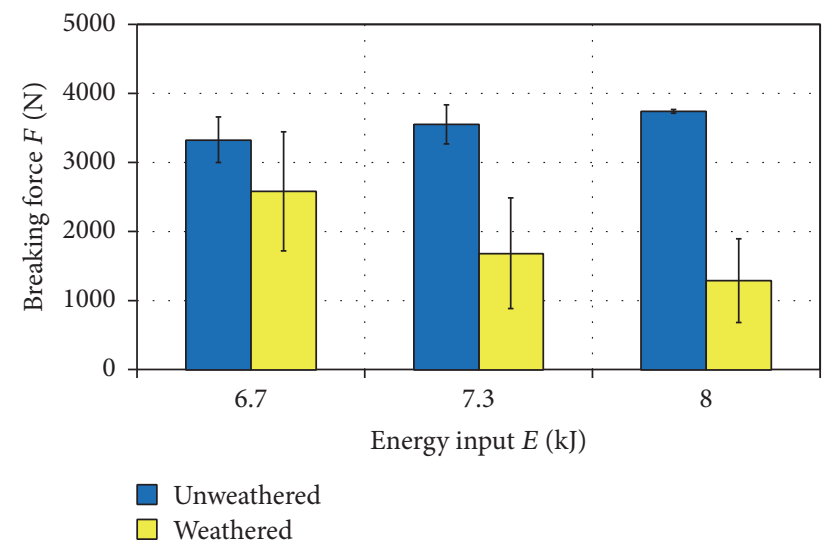

FIGURE 17: Impact of alternating climate test using PC and unalloyed steel with SLM-Structure.

of strength where the compounds show a cohesive failure, the climate stability has been an important test criterion.

On behalf of the polymers, $\mathrm{PP}$ and MABS especially were able to fulfill these requirements. For PA6.6-GF35 and PC, which cannot be joined using the transmission technique, the alternating climate test influences the material strength negatively.

The investigation of the metallic joining partner shows that the production of a compound with aluminum is significantly more complex, due to its optical and thermal properties. In comparison, unalloyed steel and stainless steel show similar properties during the joining process. Anyway, they are significantly more suitable for the production of metalplastics-hybrid compounds. The disadvantage of unalloyed steel is the corrosive behavior, which can lead to weakening of the hybrid compound with changing climate.

The observation of the different structures showed that the best results can be achieved with an SLM-Structure, whereas the results with an NRX-Structure are the worst. Using the SLM-Structure, strengths above the material strength were achieved for all used polymers. The climate changing tests resulted in a decrease of the strength of compounds with SLM-Structure as well, but only due to the effect of material strength degradation.

Further studies should especially work on improved process monitoring. Furthermore, laser optics should be developed specifically for this joining process. In this way, one can ensure that the joining zone is heated optimally and evenly. In addition, it will be discussed in the future, how, and with which processes, possible samples can be structured more efficiently.

\section{Competing Interests}

The authors declare that there are no competing interests regarding the publication of this paper.

\section{References}

[1] M. Sickert, Weiterentwicklung des wärmekontaktfügens für kunststoff-metall-verbunde [Ph.D. dissertation], RWTH Aachen, 2015.
[2] S. Scheik, Untersuchungen zum Verbundverhalten thermisch direkt gefügter Metall-Kunststoffverbindungen unter anspruchsvollen Einsatzbedingungen [thesis], RWTH Aachen University, Aachen, Germany, 2016.

[3] D. Flock, Wärmeleitungsfügen hybrider Kunststoff-Metall-Verbindungen [Ph.D. dissertation], RWTH Aachen, 2011.

[4] S. Katayama and Y. Kawahito, "Laser direct joining of metal and plastic," Scripta Materialia, vol. 59, no. 12, pp. 1247-1250, 2008.

[5] A. Roesner, S. Scheik, A. Olowinsky, A. Gillner, U. Reisgen, and M. Schleser, "Laser assisted joining of plastic metal hybrids," Physics Procedia, vol. 12, pp. 370-377, 2011.

[6] F. Balle, G. Wagner, and D. Eifler, "Ultrasonic spot welding of aluminum sheet/carbon fiber reinforced polymer-joints," Materialwissenschaft und Werkstofftechnik, vol. 38, no. 11, pp. 934-938, 2007.

[7] E. Rodríguez-Vidal, C. Sanz, C. Soriano, J. Leunda, and G. Verhaeghe, "Effect of metal micro-structuring on the mechanical behavior of polymer-metal laser T-joints," Journal of Materials Processing Technology, vol. 229, pp. 668-677, 2016.

[8] A. Tange, Y. Kawahito, S. Kubota, and S. Katayama, "Development of direct laser joining for metal and plastic," Icaleo Paper 604, 2006.

[9] J. Holtkamp, A. Roesner, and A. Gillner, "Advances in hybrid laser joining," The International Journal of Advanced Manufacturing Technology, vol. 47, no. 9-12, pp. 923-930, 2010.

[10] S. Krüger, G. Wagner, and D. Eifler, "Ultrasonic welding of metal/composite joints," Advanced Engineering Materials, vol. 6, no. 3, pp. 157-159, 2004.

[11] J. Holtkamp, M. Poggel, A. Gillner, W.-M. Hoffmann, and E. H. Walter Michaeli, "As good as welded," Kunststoffe International, vol. 98, no. 2, pp. 7-11, 2008.

[12] W. Michaeli, E. Haberstroh, W.-M. Hoffmann, and O. Grönlund, "Hybrid joints between plastics and metals by means of thermal joining processes," in Proceedings of the 24th Annual Meeting of the Polymer Processing Society, Salerno, Italien, 2008.

[13] F. Balle and D. Eifler, "Statistical test planning for ultrasonic welding of dissimilar materials using the example of aluminumcarbon fiber reinforced polymers (CFRP) joints," Materialwissenschaft und Werkstofftechnik, vol. 43, no. 4, pp. 286-292, 2012.

[14] F. Balle, S. Huxhold, G. Wagner, and D. Eifler, "Damage monitoring of ultrasonically welded aluminum/CFRP-joints by electrical resistance measurements," Procedia Engineering, vol. 10, pp. 433-438, 2011.

[15] F. Balle, G. Wagner, and D. Eifler, "Ultrasonic metal welding of aluminium sheets to carbon fibre reinforced thermoplastic composites," Advanced Engineering Materials, vol. 11, no. 1-2, pp. 35-39, 2009.

[16] G. Wagner, F. Balle, and D. Eifler, "Ultrasonic welding of hybrid joints," The Member Journal of The Minerals, Metals Materials Society, vol. 64, no. 3, pp. 401-406, 2012.

[17] P. Mitschang and R. Velthuis, Process Parameters for Induction Welding of Metal/Composite Joints, ECCM-13, Stockholm, Schweden, 2008.

[18] P. Mitschang, R. Velthuis, S. Emrich, and M. Kopnarski, "Induction heated joining of aluminum and carbon fiber reinforced nylon 66," Journal of Thermoplastic Composite Materials, vol. 22, no. 6, pp. 767-801, 2009.

[19] Y. Kawahito and S. Katayama, "Innovation of laser direct joining between metal and plastic," Transactions of JWRI, vol. 39, no. 2, pp. 50-52, 2010. 
[20] W. Tillmann, A. Elrefaey, and L. Wojarski, "Toward process optimization in laser welding of metal to polymer," Materialwissenschaft und Werkstoffechnik, vol. 41, no. 10, pp. 879-883, 2010.

[21] A. Bauernhuber and T. Markovits, "Laser assisted joining of metal pins and thin plastic sheets," Physics Procedia, vol. 39, pp. 108-116, 2012.

[22] J. P. Bergmann and M. Stambke, "Potential of Laser-manufactured Polymermetal hybrid Joints," Physics Procedia, vol. 39, pp. 84-91, 2012.

[23] D. Flock, E. Haberstroh, A. Rösner et al., "Starke verbindung ungleicher partner," Kunststoffe, vol. 11, no. 112, pp. 60-63, 2010.

[24] J. Holtkamp, M. Poggel, A. Gillner, W.-M. Hoffmann, and E. H. W. Michaeli, "As good as welded," Kunststoffe International, vol. 98, no. 2, pp. 7-11, 2008.

[25] S. Katayama, Y. Kawahito, and M. Mizutani, "Latest progress in performance and understanding of laser welding," Physics Procedia, vol. 39, pp. 8-16, 2012.

[26] A. Rösner, A. L. Boglea, and A. Olowinsky, "Laserdurchstrahlschweißen von thermoplasten," Laser Technik Journal, vol. 5, no. 4, pp. 28-32, 2008.

[27] R. Schmitt, G. Mallmann, P. Ackermann, J. P. Bergmann, M. Stambke, and K. Schricker, "3D-charakterisierung von hybridbauteilen durch OCT," Werkstattstechnik, vol. 105, no. 11-12, pp. 764-769, 2015.

[28] E. Haberstroh and M. Sickert, "Thermal direct joining of hybrid plastic metal componets," KMUTNB International Journal of Applied Science and Technology, vol. 7, no. 3, pp. 29-34, 2014.

[29] P. Kah, R. Suoranta, J. Martikainen, and C. Magnus, "Techniques for joining dissimilar materials: metals and polymers," Reviews on Advanced Materials Science, vol. 36, no. 2, pp. 152164, 2014.

[30] K. Schricker, M. Stambke, J. P. Bergmann, K. Bräutigam, and P. Henckell, "Macroscopic surface structures for polymer-metal hybrid joints manufactured by laser based thermal joining," Physics Procedia, vol. 56, pp. 782-790, 2014.

[31] A. Bauernhuber and T. Markovits, "Investigating thermal interactions in the case of laser assisted joining of PMMA plastic and steel," Physics Procedia, vol. 56, pp. 811-817, 2014.

[32] C. H. R. Brecher, Integrative Produktionstechnik für Hochlohnländer, Springer, Heidelberg, Germany, 2011.

[33] C. H. R. Pickert and M. Wirth, Additive Fertigungsverfahren, vol. 1, Julius Maximilians Universität Würzburg, CEDIFA Arbeitsbericht, 2013.

[34] DIN ISO 527, KUNSTSTOFFE: Bestimmung der Zugeigenschaften, Beuth, Berlin, Germany, 1996.

[35] M. Bonnet, "Wärmebeständigkeit," in Kunststoffe in der Ingenieuranwendung: Verstehen und Zuverlässig Auswählen, M. Bonnet, Ed., Vieweg und Teubner, Wiesbaden, Germany, 2009.

[36] DIN IEC 60068-2-38: Grundlegende Umweltprüfverfahren; Teil 2: Prüfungen, Prüfung Z/AD: Zusammengesetzte Prüfung, Temperatur/Feuchte, zyklisch, Beuth, Berlin, Germany, 1979.

[37] U. Berlich, Alterung und rissbildung unter medieneinfluss bei polycarbonat [Dissertation], RWTH Aachen University, Aachen, Germany, 2004. 

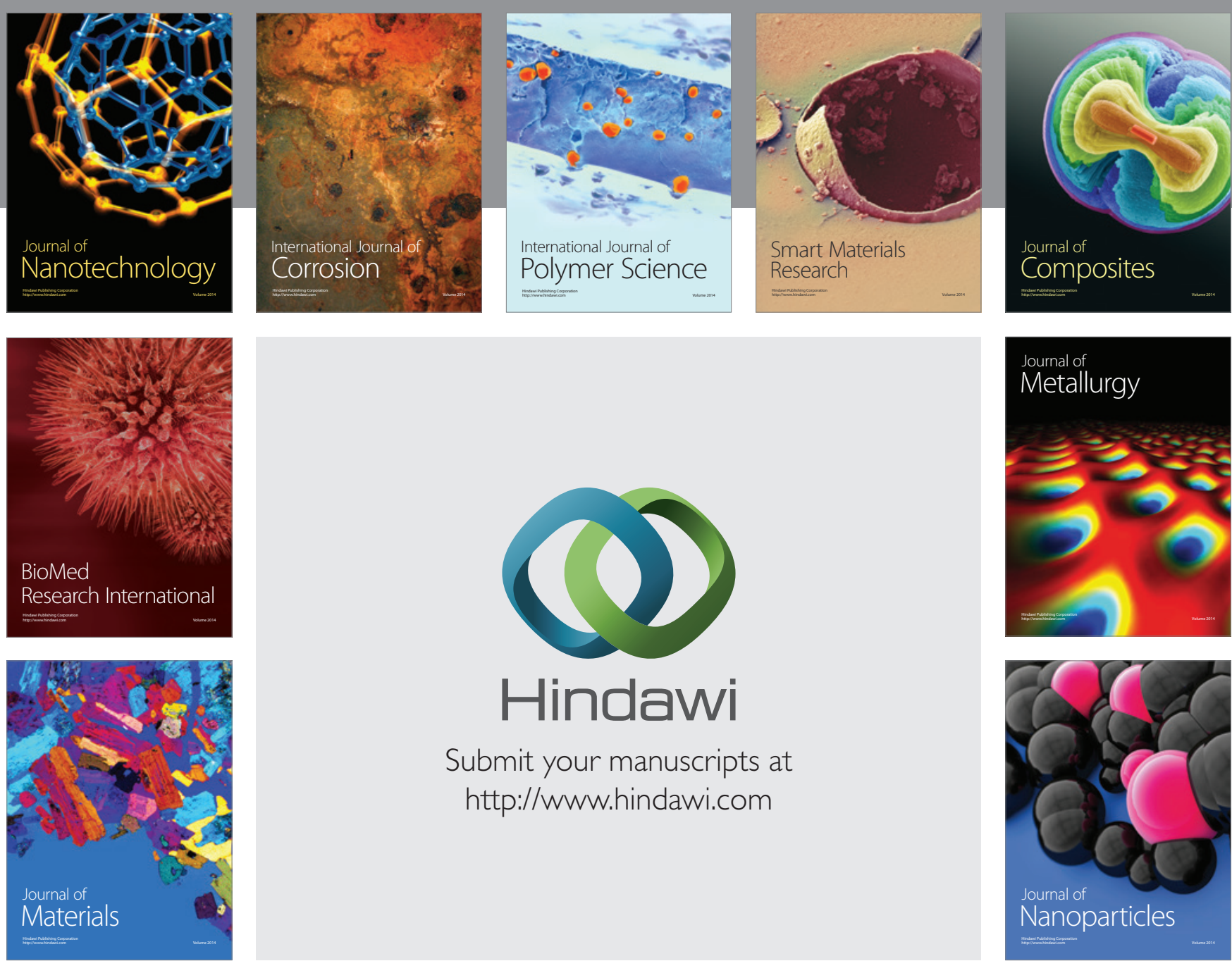

\section{Hindawi}

Submit your manuscripts at

http://www.hindawi.com

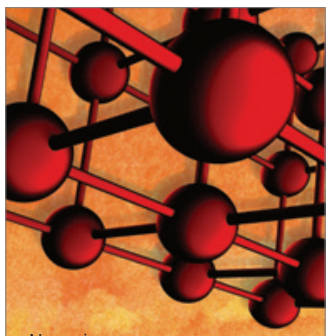

Materials Science and Engineering
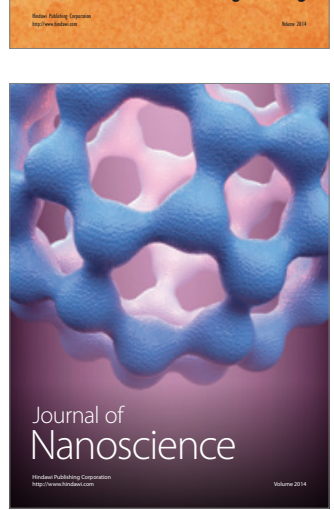
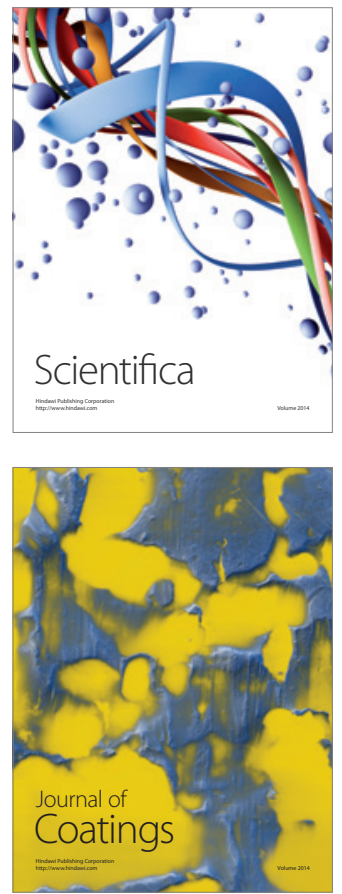
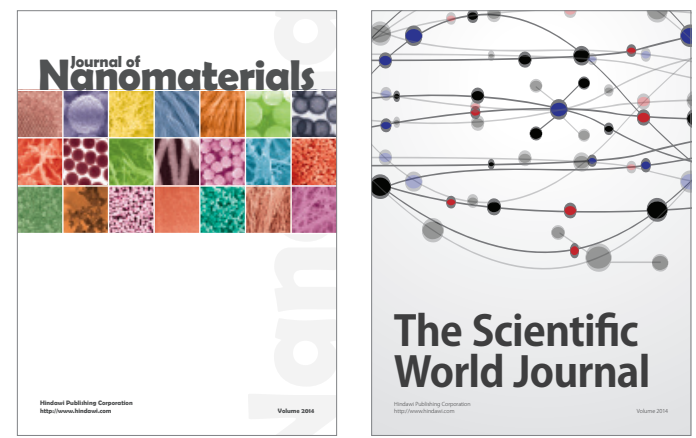

The Scientific World Journal
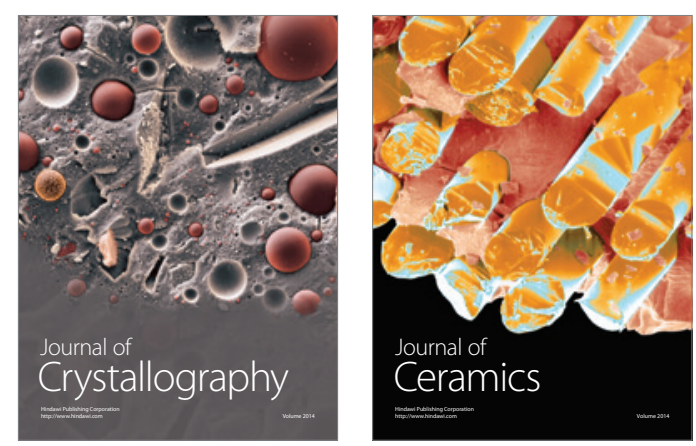
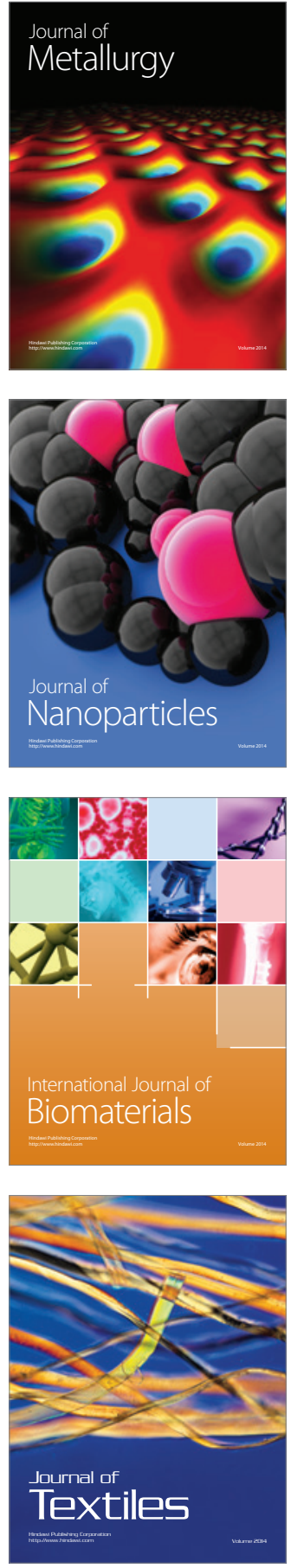